\title{
Mitigating the Impact of a Financial Crisis: Some Lessons from Hong Kong During the 1997 Asian Financial Crisis
}

\author{
Ruoxi Zhang \\ University of New South Wales, Australia \\ Satish Chand \\ Professor, University of New South Wales, Australia
}

Doi:10.5901/ajis.2013.v2n8p285

\begin{abstract}
The year 1997 was a major milestone for Hong Kong: it experienced the height of the Asian financial crisis; and, it was the very year when the sovereignty was handed back from the UK to China. Hong Kong citizens viewed the handover with mixed feelings under the crisis circumstances: pride in reunification and uncertainty over the future. This study systematically assesses the formation, development and importance of Hong Kong's monetary system, its integration with mainland China, and the position of the City-State as an international financial centre. We use data collected through fieldwork and guided by the literature to analyse reasons why Hong Kong managed to escape the worst of the impact of the Asian Financial Crisis. Interviews were conducted with informed commentators and senior bureaucrats in Hong Kong, mainland China and Australia to assess- the effectiveness of Hong Kong's monetary system, the feasibility of the "One country, two systems" proposal, and the integration between Hong Kong and mainland China. Our findings provide support to the proposition that Hong Kong was successful in defending its currency against speculators, stabilising its currency through policy interventions, and in the process strengthening its position as an international financial centre.
\end{abstract}

Keywords: Asian financial crisis, Hong Kong, HKMA, monetary system, linked exchange rate

\section{Introduction}

The year 1997 was special to Hong Kong. It simultaneously experienced the reunification with mainland China and the Asian financial crisis (AFC). These events brought mixed feelings to Hong Kong citizens: honour on returning to the home country and uncertainty over the future. In hindsight however, most of the apprehension was unnecessary. Hit by speculative attacks and regional spill over, Hong Kong still managed to maintain its linked exchange rate and strengthen its position as an international financial centre. Regarding Hong Kong's defensive activities, several typical questions have been raised: With alternative options, why did Hong Kong insist on defending its exchange rate regime? Why did not Hong Kong simply prohibit the currency convertibility to draw back hostile speculative attacks? Why was the Mainland cautious in intervening in Hong Kong at that time? How did Hong Kong mitigate the impact of the financial crisis? Trying to answer these questions, this paper assesses the importance of the Hong Kong financial system and the influences from mainland China amid the AFC with the use of information collected from fieldwork.

\section{Data}

In order to evaluate Hong Kong's monetary intervention and exchange rate policy during the 1997 Asian financial crisis, fieldwork was conducted from November 2012 to January 2013 in Australia, Shanghai, and Hong Kong sequentially. Face to face semi-structured interviews were carried out with 20 informed scholars and officials. They shared their viewpoints on numerous topics regarding the impact of the AFC on Hong Kong in 1997. The subjects covered included: Hong Kong's economic performance in the crisis in comparison with other regional economies, assessment of the range and effectiveness of the interventions of the Hong Kong Monetary Authority (HKMA), suitability of the currency board (linked exchange rate system) during and after the crisis, China's influences on Hong Kong during the crisis, and the prevention of future crises. 


\section{Analysis}

Since the handover in 1997, there have been two systems coexisting in mainland China and Hong Kong. This is widely known as the "One Country, Two System" policy. Like the political system, Hong Kong's monetary system is also relatively independent of, but closely interrelated with that of mainland China. The existence of two monetary regimes based on the Renminbi (RMB) and the Hong Kong dollar (HKD) respectively is promoting the mutual development of the Mainland and Hong Kong. Hong Kong has its own currency, monetary system and monetary authority. China is keeping its promise on maintaining Hong Kong's autonomy. With data collected from fieldwork and the extant literature, this paper critically analyses Hong Kong's financial system and its core players: the HKMA, the Currency Board, the Exchange Fund, the interrelation with mainland China, and Hong Kong's status as an international financial centre.

\subsection{The HKMA}

The Hong Kong Monetary Authority (HKMA) serves the functions of a central bank in most other jurisdictions. Its functions can be briefly described as: maintaining currency stability, promoting the integrity of the financial system, reinforcing Hong Kong's status as an international financial centre, and managing the Exchange Fund (HKMA, 2012). Since 1983, Hong Kong has been pegging its currency to the US dollar (USD) at 7.8 HKD per USD, which is called the linked exchange rate system. The exchange rate system supports Hong Kong's international trade, service industry, and its status as a financial centre. One of the HKMA's major roles is to strengthen and develop the currency board to make it more rule-based and transparent.

During the AFC, the major steps the HKMA took were interventions on the stock market. These interventions were more frequent at the height of each speculative attack, and with the benefit of hindsight proved to be effective in protecting the linked exchange rate, and restoring the financial market, although at the expense of soaring interest rates and slumps in the stock market.

In the fieldwork, several interviewees provided their opinions on the HKMA's performance in the crisis. In general, most scholars made favourable comments on the Hong Kong government and the HKMA in those special years. Specifically, the HKMA's success in protecting the linked exchange rate and maintaining information transparency was positively evaluated by Professor Bill Hung. One significant manifestation was the reduced panic as a result of appropriate and measured responses by the HKMA. Hung believes what the HKMA did is worth studying as a typical case by other central banks (Hung, 14 January 2013). An anonymous official from the HKMA also values the responses as relatively successful, especially the stock market interventions in 1998. He indicated that the HKMA was taking a lot of risks in this controversial move. Although there had been no guarantee before it was implemented, it proved right later. To strengthen the credibility of the currency board regime, seven technical measures were introduced after the height of the crisis ${ }^{1}$. The HKMA has been striving to build a more robust and transparent regime, and to ensure a strong risk management framework in Hong Kong's banking system (Anonymous, 14 January 2013).

Different from the above view, some professors think the HKMA was somewhat slow in responding when the crisis hit. Professor David Cook argues the lack of an open discount window reduced the credibility in inter-bank markets, leading to an extremely low level of liquidity in the markets. Cook asserted that the HKMA did things right ultimately; but in hindsight, it took a longer time to fix the technical change to the discount window and solve the liquidity problem than was necessary (Cook, 17 January 2013).

\subsection{Currency board}

A currency board (CB) is a special form of monetary institution. Under this system, the HKMA can only issue domestic notes backed by $100 \%$ with foreign exchange reserves (Tse \& Paul, 2003). The board has the obligation to exchange local currency with major foreign currencies on request, and vice versa. There is no discretionary monetary policy. Money supply and interest rates are determined by the market. The CB in Hong Kong is popularly known as the linked exchange rate system.

The CB has its pros and cons. The main advantages are effectively the same with those inherent in a fixed

1 For details, see Reference Materials on the HKMA website: http://www.hkma.gov.hk/eng/publications-and-research/referencematerials/viewpoint/19990930.shtml 
exchange rate system. Assurance of currency convertibility can reduce foreign exchange risks faced by traders and investors; high requirement of macroeconomic discipline assures prudential fiscal policy; it can also help promote public confidence in the financial market in the long run (Kang, 2000). This provides a credible assurance to low inflation rate and encourage economic growth. However, the CB also has its drawbacks, as Li puts it, there is no independent monetary policy that can be based on a country's own situation, and the economy is poorly immune to external shocks (Li, 2012a).

There have been a number of debates and critics on Hong Kong's CB arrangement. Some believe the fixed exchange rate regime has always been, and will be the most appropriate for Hong Kong as a small open economy. The maintenance of the linked exchange rate regime during the AFC enhanced public confidence on Hong Kong's currency and beat speculation. Others propose alternative solutions for Hong Kong's exchange rate, such as managed fixed, managed floating, or a broader band in which the exchange rate can be adjusted. Some interviewees' points of view are presented to make a comparison.

The scholars who approve the current exchange rate regime believe that the linked exchange rate is the most effective and workable regime for Hong Kong. Professor Kui Wai Li thinks there is nothing as a perfect system. The best system is the one providing the most foreseeable result. Li gives credit for Hong Kong's peg because it is doing this job. By linking to the USD, he postulates that we can assure the certainty of the international currency. Admittedly, Hong Kong has the problem of no independent monetary policy. However, even if the HKD were not linked to the USD, it would still have to follow the US in effect, as the whole world does (Li, 18 January 2013). Similarly, Professor Vincent Mok considers there would have been no way to ensure an exchange rate system better than the current peg. Since Hong Kong is a small open economy, a free float might have made Hong Kong suffer more during the AFC (Mok, 8 January 2013).

On the contrary, some other professionals feel that there could be a better regime than the linked exchange rate. Professor Warwick McKibbin thinks the big problem faced by Hong Kong was the peg to the USD, which meant they needed to have a real depreciation at probably $30-40 \%$ during the crisis. Instead of having the depreciation through the exchange rate, they had to achieve it through deflation. So the big collapse in the price of goods and assets was very costly. It could have been better if the exchange rate were allowed to fall like it did in Australia (McKibbin, 30 January 2013).

The existing debates on Hong Kong's most appropriate exchange rate regime necessitate the study and proposal of other options. Professor Lok Sank Ho holds the opinion that the peg should have been replaced by a managed fixed exchange rate. His theoretical framework is that the exchange rate has to be conditional on fundamentals. Without evidence for changes in fundamentals, the exchange rate should be kept fixed. When there is sufficient evidence to justify fundamental changes, it is time to adjust the exchange rate (Ho, 10 January 2013).

\subsection{Exchange Fund}

The Exchange Fund plays its role directly or indirectly affecting the exchange value of Hong Kong currency, as well as keeping the stability of the monetary system, and maintaining Hong Kong as an international financial centre. Assets in the Fund are managed actively on a day-to-day basis. To keep it in line with its mission and role, the HKMA reviews its investment strategies and styles on a regular basis.

Assets in the Exchange Fund are segregated in two different portfolios. One is the Backing Portfolio, which ensures that the Hong Kong currency is fully backed by the USD; the other is the Strategic Portfolio for strategic purposes. These portfolios are created to keep liquidity and generate returns (HKMA, 2012a). In accordance with the Exchange Fund Ordinance, the Financial Secretary, who is in control of the Exchange Fund, is required to consult the Exchange Fund Advisory Committee (EFAC). The Financial Secretary is in charge of appointing members, including the HKMA, in view of their individual capacity, such as expertise, knowledge, and experience. EFAC provides advice for the Financial Secretary on return generated by the Fund, and expenditure from the Funds, particularly the investment strategies, and the development of the financial infrastructure (HKMA, 2013). Professor Che Cheong Poon considered the EFAC to be the party which contributed most significantly in defending against speculators (Poon, 14 January 2013).

\subsection{Economic interaction with mainland China}

Regarding the role China played in helping Hong Kong defend its currency, there is consensus among scholars. They all agree on China's commitment to RMB stability and its strength in backing the HKD with ample foreign reserves. An anonymous official in the HKMA defines China's assistance as moral support during the crisis, with few specific policies 
(Anonymous, 14 January 2013). Another interviewee, Professor Ho, gives a high evaluation of China's role in the crisis. He believes RMB with no devaluation prevented the regional spill-over of the crisis. According to Professor Ho, China's strong economic growth enabled more import absorption. Regional exports to mainland China led the economic recovery in neighbouring countries (Ho, 10 January 2013).

At the time of the AFC, China was not as much involved in Hong Kong's issues as it has been since 2003. The reason why China was cautious in intervening in Hong Kong was that Hong Kong experienced both the financial crisis and the political handover at the same time. This was a double shock to Hong Kong citizens, who had more uncertainty about their future. The best way to enhance investors' confidence and social stability was to keep things as normal as possible. This opinion was confirmed by one of my interviewees, Professor Che Leung Kwong (Kwong, 11 January 2013). China did try its best in backing up Hong Kong and maintaining the regional stability. During the turmoil, the central authority in Beijing pledged that the RMB would not be devalued (Gurtner, 1999). These commitments helped Hong Kong repel continual speculation, and stopped further competitive depreciation and spread of the panic. Hong Kong was overwhelmed by credit squeeze after massive defence of the peg (Kueh \& Raymond, 2002). According to Kueh \& Raymond, the Mainland granted the first ever RMB credit and a value-added tax rebate to provide liquidity and sustain export activities to provide first-hand rescue.

Since the third quarter of 1999, Hong Kong's economy had begun to recover remarkably, bound up with the rebound of the Mainland's revival in exports. China has been increasingly important as Hong Kong's main trading partner since the 1980s. Within the ten years from 1986, the US share of Hong Kong's exports fell from $41.7 \%$ to $25.4 \%$, while mainland China rose from $11.7 \%$ to $29 \%$. Since before the crisis occurred, China had been the primary trading partner of Hong Kong. Table 1 shows Hong Kong's main trade destinations and suppliers from 1996 to 1999.

Table 1: Main Trading Partners, 1996-1999 (\% of total)

\begin{tabular}{|c|c|c|c|c|c|c|c|c|}
\hline & \multicolumn{4}{|c|}{ Exports to } & \multicolumn{4}{c|}{ Imports from } \\
\cline { 2 - 9 } & 1996 & 1997 & 1998 & 1999 & 1996 & 1997 & 1998 & 1999 \\
\hline China & 34.2 & 34.9 & 34.4 & 33.3 & 37.1 & 37.7 & 40.6 & 43.6 \\
\hline US & 21.2 & 21.7 & 23.4 & 23.8 & 7.9 & 7.8 & 7.5 & 7.1 \\
\hline Japan & 6.5 & 6.1 & 5.2 & 5.4 & 13.6 & 13.7 & 12.6 & 11.7 \\
\hline Germany & 4.2 & 3.9 & 3.9 & 3.9 & 2.2 & 2.4 & 2.3 & 2.0 \\
\hline UK & 3.3 & 3.4 & 3.9 & 4.1 & - & - & - & - \\
\hline Taiwan & 2.4 & 2.5 & 2.5 & 2.4 & 8.0 & 7.7 & 7.3 & 7.2 \\
\hline Singapore & 2.7 & 2.6 & 2.3 & 2.4 & 5.3 & 4.9 & 4.3 & 4.3 \\
\hline
\end{tabular}

Source: Census and Statistics Department, HKSAR

\subsection{Hong Kong as an international financial centre}

Hong Kong is achieving remarkable progress in financial infrastructure development and has continued a reinforced role as a competitive international financial centre. The improvement is reflected by the sovereign credit ratings by major international credit rating agencies, namely, Standard \& Poor's and Moody's Investors Service. Also, the HKMA works to present the economic and financial developments to the credit agencies to make them understand Hong Kong's economic health. This has resulted in upgrading in credit ratings over the past several years (HKMA, 2011).

Hong Kong manifests its reinforced position as an international financial centre in the increasing net foreign assets (Figure 1). The volume of net foreign assets increased from USD 62 billion in 1991 to USD 511 billion in 2011, though it experienced a slight drop in 2008 when the global financial crisis began. Singapore is chosen as a comparable economy, because Hong Kong and Singapore are both small open economies and have many economic similarities. Compared to Singapore, Hong Kong's net foreign assets have increased since the World Bank records began in 1991, and the disparity between the two has grown significantly since the crisis. 
Figure 1: Net foreign assets of Hong Kong and Singapore (1991-2011) (in USD billion)

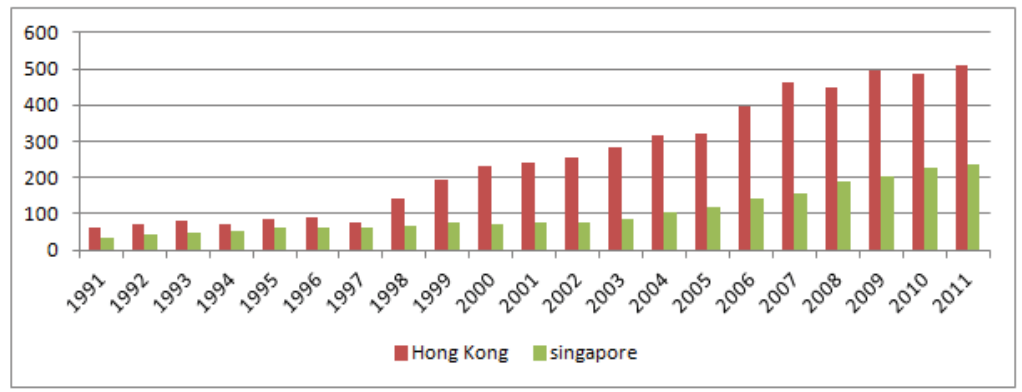

\section{Source: World Bank data}

The reinforcement of Hong Kong's status as an international financial centre is also displayed in several other aspects. First is the increasing international and regional cooperation and integration. Many of the efforts focus on economic growth and financial stability under the changing international situation and upcoming events. Massive achievements have been made on global regulation reforms by relevant recommendations and implementation. The second aspect lies on ensuring monetary and financial stability in Asia. Careful analysis is conducted on the region's risks and vulnerability. The HKMA frequently consults with counterparts on the soundness of the macroeconomic and financial sectors. Third, Hong Kong commits itself as the offshore RMB business centre (HKMA, 2011). So far, Hong Kong's development as one of the most important RMB offshore business centre has achieved great success in different dimensions. The growth of RMB deposits in Hong Kong is shown in Figure 2. The total RMB deposits increase from RMB 12 billion at the end of 2004 to RMB 603 billion at the end of 2012. Hong Kong now hosts the largest offshore RMB liquidity pool.

Figure 2: RMB deposits in Hong Kong (in RMB billion yuan)

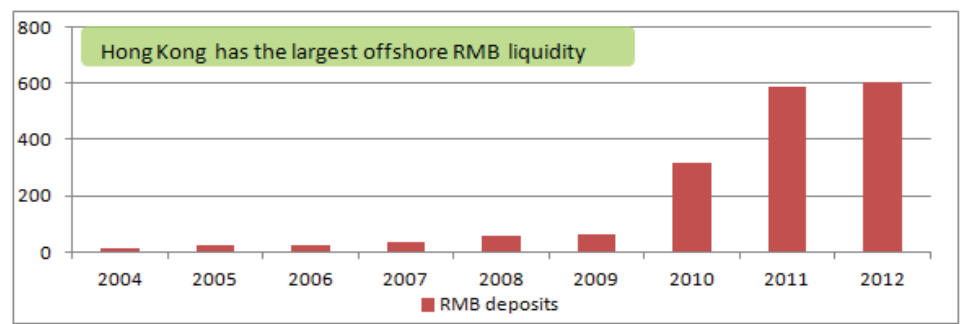

Source: HKMA data

Fourth, the signing and implementation of CEPA closely connects Hong Kong economic booms with mainland China. In 2006, the inflow and outflow of Hong Kong's foreign direct investment with the Mainland were HKD 108.7 billion and HKD

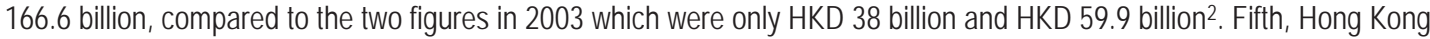
works closely with the Mainland to provide cross-border payment links. The cross-border links facilitated more than 20,000 transactions between Hong Kong and two Mainland regions, Shenzhen and Guangdong in 2011 (HKMA, 2011). It allows safe and efficient payments in HKD and USD.

One commonly raised question on Hong Kong's response to speculative attack is why Hong Kong did not just simply prohibit the conversion of the HKD to the USD to restrain speculation in the crisis. The answer is simple: to maintain Hong Kong's status as the international financial centre. To quote an official from the HKMA: "Hong Kong had always been an international financial centre. We did not expect to control capital and damage this reputation, which takes a rather long time to establish (Yuen, 8 January 2013)." For this purpose, Hong Kong did not discourage the convertibility of the Hong Kong currency with fierce currency attacks.

\footnotetext{
2 Data are from the Census and Statistics Department, Hong Kong SAR.
} 


\subsection{Mitigating the impact of the financial crisis}

Financial crises impact adversely on the economy, especially in developing countries. Millions of people lost their jobs and were catapulted into poverty by the financial crises. To mitigate negative influences, experts propose preventive and responsive measures to future financial crises in Hong Kong and regional economies.

In an interview with Professor Tai Leung Chong, he stated that the best way to prevent a crisis is establishing a robust financial system. It is important to protect unsophisticated investors, and strengthen investors' confidence (Chong, 10 January 2013). In another interview, Professor Ho argued there are a lot of links in the global financial market. Problems on any link could spread to others. Therefore a future financial crisis is inevitable. What we can do is to make full preparation when the markets are calm. A set of well-designed tools are useful in responding to crisis $(\mathrm{Ho}, 10$ January 2013). An interviewee in Australia, Professor Ligang Song, looks forward to the integration of mainland China and Hong Kong to mitigate risk. When the RMB becomes internationalised and China's capital account is convertible, many problems will be solved (Song, 14 November 2012). In a similar vein, Professor Jianping Ding attributed the occurrence of the AFC to inadequate banking supervision. He thinks administrative measures are necessary to cope with malicious speculation (Ding, 18 December 2012). In addition, another interviewee, Professor Thomas Hugh believes that creditability is extremely important to financial system. Hong Kong should work on strengthening its central bank regime, ensuring transparency, and not changing policies rapidly or when put under pressure (Hugh, 9 January 2013).

\section{Conclusion}

This paper has summarised the views of several informed commentators on Hong Kong's financial system and its interconnection with mainland China, explaining reasons how these linkages helped Hong Kong survive the AFC. The viewpoints of scholars and officials are presented and discussed regarding the performance of the HKMA, the importance of the currency board, influences from China, and its position as an international financial centre.

The key findings of the research presented in this paper are: (1) by maintaining the linked exchange rate regime during the crisis, Hong Kong was able to insure the certainty of the HKD, and thus provide economic stability in the face of a regional currency crisis; (2) the Hong Kong authority did not forbid currency convertibility to avoid damaging its position as a financial centre; (3) mainland China provided more moral support than specific measures to keep Hong Kong's economic and social stability; (4) to mitigate the adverse impact of a financial crisis, Hong Kong should closely work with mainland China and regional countries, enhance financial supervision, strengthen the central bank regime to maintain creditability.

In conclusion, Hong Kong was successful in defending against speculative activities and protecting the HKD without compromising its status as a financial centre. It stepped into the financial market with abundant foreign reserves and firm backing from China. Questions remain about the appropriate exchange rate regime for Hong Kong, and a possible and more efficient way to survive a financial crisis. Future studies could be conducted on alternative exchange rate system proposals for Hong Kong, and how to prevent future financial crises.

\section{References}

Gurtner, F. (1999). The stability of the Renminbi in the wake of the Asian financial crisis. Intereconomics, 34(3), 135-143.

HKMA. (2011). HKMA Annual Report 2011.

HKMA. (2012). An Introduction to the Hong Kong Monetary Authority.

HKMA. (2012a). Exchange Fund. Retrieved 19/03, 2013, from http://www.hkma.gov.hk/eng/key-functions/exchange-fund.shtml

HKMA. (2013). The Exchange Fund Advisory Committee. Retrieved 19/03, 2013, from http://www.hkma.gov.hk/eng/about-thehkma/hkma/advisory-committees/exchange-fund-advisory-committee.shtml

Kang, H. P. (2000). Is a currency board an answer to Asia's currency crisis? Managerial Finance, 26(4), 49.

Kueh, Y. Y., \& Raymond, C. W. N. (2002). The interplay of the "China factor" and US dollar peg in the Hong Kong economy. The China Quarterly(170), 387.

Li, K. W. (18 January 2013). Personal interview.

Li, K. W. (2012a). Economic Freedom: Lessons of Hong Kong World Scientific Publishing Company, Incorporated.

Tse, Y. K., \& Paul, S. L. Y. (2003). The impacts of Hong Kong's Currency Board reforms on the interbank market. Journal of Banking \& Finance, 27(12), 2273. 